ASSESSNENT OF ACCIDENT ENERGETICS IN IMFBR CORE-DISRUPTIVE ACCIDENTS

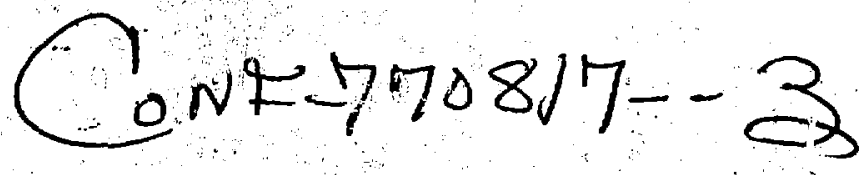

H. K. Fauske

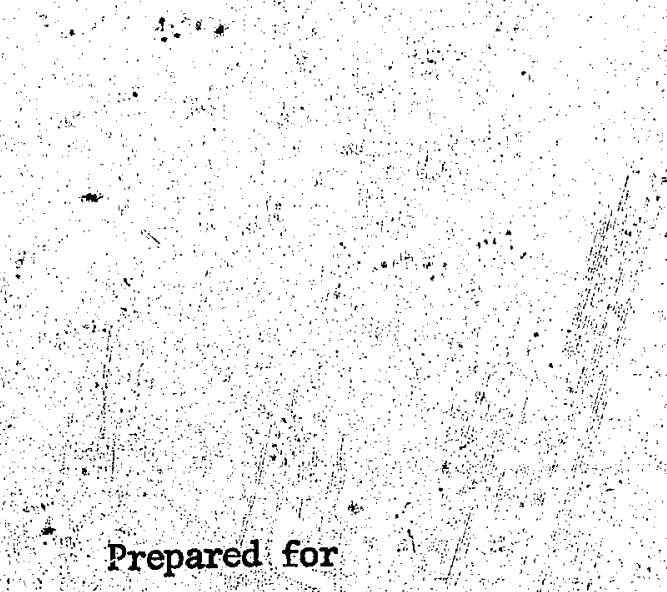

International Seminar on

Contaimment of Fast Breeder Reactors

San Francisco, CA

Auguist 22-23, 1977

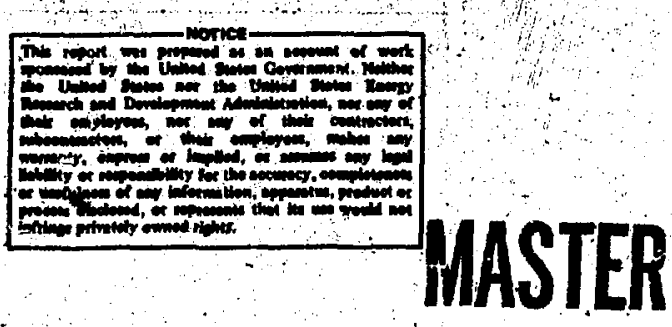

DISTRIBUTION OF THIG DOCUMENT IS UNLIMITED

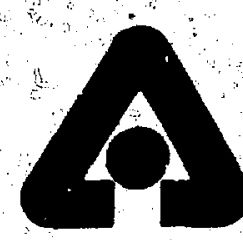

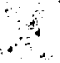

.

ARGONNE NATIONAL LABORATORY, ARGONNE, ILLINOTS

operated under contract W-31-109-Eng-38 for the

U. S. ENERGY RESEARCH AND DEVELOPMENT ADMINISTRATION 


\section{ASSESSYENT OF ACCIDENT ENERGETICS IN LMFBR CORE-DISRUPTIVE ACCIDENTS}

H. K. Fauske

Angonine Nationat Laboratory

Reactor Analysis and Sabety pivision

9700 South cass Avenue

Angonne, Ileinois 60439 ucs

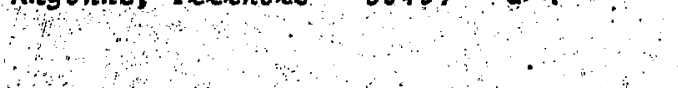

in assesswent of accident energetics in IMFBR core-disruptive accidents is given with enphatis on the generic issues of energetic recriticality and energetic fuei-cooiant interaction events. Application of a few general behavior principles to the oxide-fueled system suggest that such events are highly unlikely following a postulated core meltdown event.

\section{Introduction and Overall Approach}

The basic protection to the public from fast reactors as from all other "reactor types against the escape of radioactive material is through a multiplicity of barriers, e.g., pin cladding, subassembly structures, the reactor primary system, cleanup systems, and the secondary containment system: In addition to these engineered barriers, there may be other inherent or natural barriers or attenuators such as meteorological disperion. Furthermore it shoula be clear that the issue of public safety or envirommental risk from fast reactors like for thermal reactors can ónly enter through the hypothetical core-aisruptive accident (fCDA), e.g all accldents of algnificance to the environmant lead to a core melt resulting in breach of the engineered barriers associated with the core disfuption (leading to rapid release of radioactive materials) or from thermal meltthrough due to continued decay heat generation (leading to radioactive release at a relatively later time : It is only with respect to acc dent energetics that IMFBRs differ significantly . from. INRs. This \&s not because the probability of an accident ig any greater for the IMFBR, but because the accidents that require analysis have been quite different in character Unlike LWRs, IMFBRs can be very sensitive to dimensional changes or relocation of core materials ince the intact IMFBR core is not in its most reactive configuration. Therefore. it is theoretically possible that rearzangemert of geometry can lead to prompt- critical reactivity excursions and to hy drodynamic disassembiy of the reactor resulting in large quantities of vaporized fuel, as first discussed by Bethe and Tait in 1956,[1] which raises the general issue of energetic recriticality accidents A typical idealized configuration used to produce an upper-bound limit on the recriticality excursion is shown in Fig. 1, where the upper portion of the core following an arbitrary separation is assumed to fall by gravity onto the lower portion of the molten core The relatively greater concern voiced over IMFBR core meltdown accidents results therefore principally. from its significancly increased potential for producing vaporized plutonium (airborne fuel particles) and breach of the engineered barriers due to a violent disassembly accident. only the recriticality issue is unique to the IMFBR and other fast reactors. Also, even if a core meltaown occurs without an energetic excursion, the possibility of an energetic fuel-coolant interaction. (vapor explosion) muat be considered, as first aiscussed by Hicks and Menzies in 1965. [2] An upper-bound estimate as used by Hicks and Menzies requires the idealiaed configuration iliustrated in FIg. 1 where the molten fuel and liquid sodiun must be finely mixed to resuit in optimun and instantaneous transfer of energy: Ever ince Bethe-Tait and Hicks-Menziea studies, the assessment of CDAs, including recriticality and fuel-coolant interaction events, has beej a major consideration in INFBR safety analysi: and development This is because it is. generally not considered practical to..- 


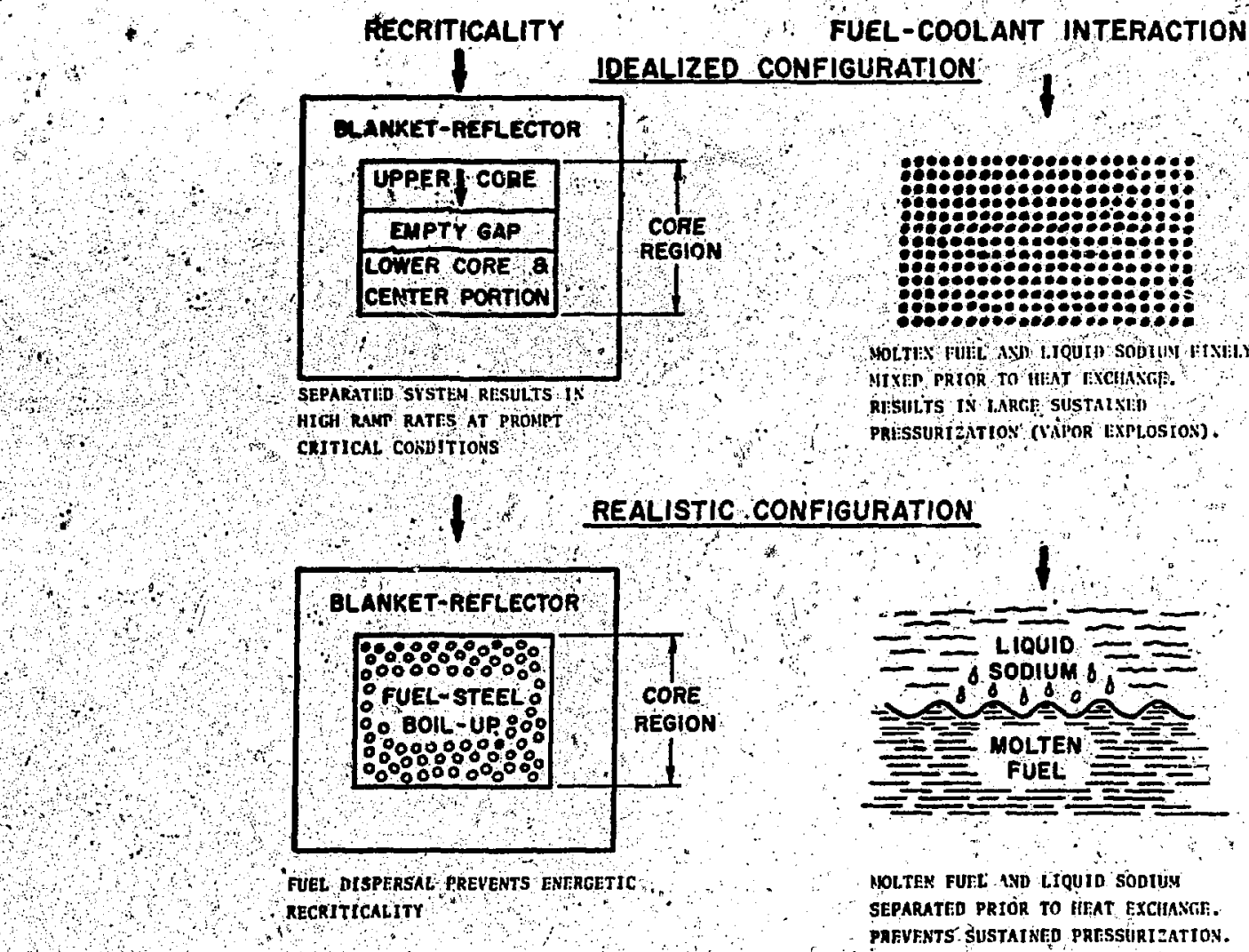

FUEL-COOLANT INTERACTION

Ig. 1. Accidert Energeties - Generic Issues.

accommodate upper theoretica] bounds resulting from idealized configurations as Illustrated in Fig. 1. Furthermore, - ince the levels of energetias resulting from hydrodynamic disassembly are rather censitive to small variations in the core average temperature (the work is essentialiy proportional to fuel vapor presare which is an exponential function of temperature) and hence to initial conditione like the driving ramp rate, it follow that it is desirable to be able to rule out energetic hydrodynamic disas sembly conditions altogether. [3] For example, Fig. 2 illustrates slightly different idealized recriticality configuratione Lhcluding both gravity and preswre driven collapse nodes and associated work potential for the f'ast Flux Test Facility. (PFTF). If these conditions ware indeed realistic, it would be difficult if not impossibie to sort out the difference between rame rates of $100 \mathrm{~s} / \mathrm{s}$ and $125 \% / \mathrm{s}$ wich lead to an increase in work potentidil by factor of 2. It would therefore be correspondingly unrealistic to clalm that FFTF is providing any elgnificant safety margin for the conditions illustrated in Fig. 2 .
Adequate safety margins are rather assured by illustrating that highly energetic recriticality, events are very uniikely. Similar arguments can be mảde relative to energetic fuel-coolant interaction events. One can perhaps think of three possible ways to resolve the generic issues associated with an LMFBR meltdown accident:

- Detailed mechanistic approach* uning large complex computer codes tracking the accident sequentially from the initiating phase to a permanent subcritical and coolable fuel configuration with radiological consequence assessment.

- Large-scale test(s) involving an integrated sequence of events (imulating an LOF accident, etc.).

- Assessment of the core-meltaown process based on a limited number of "general behavior principles," which are verified experimentally. 

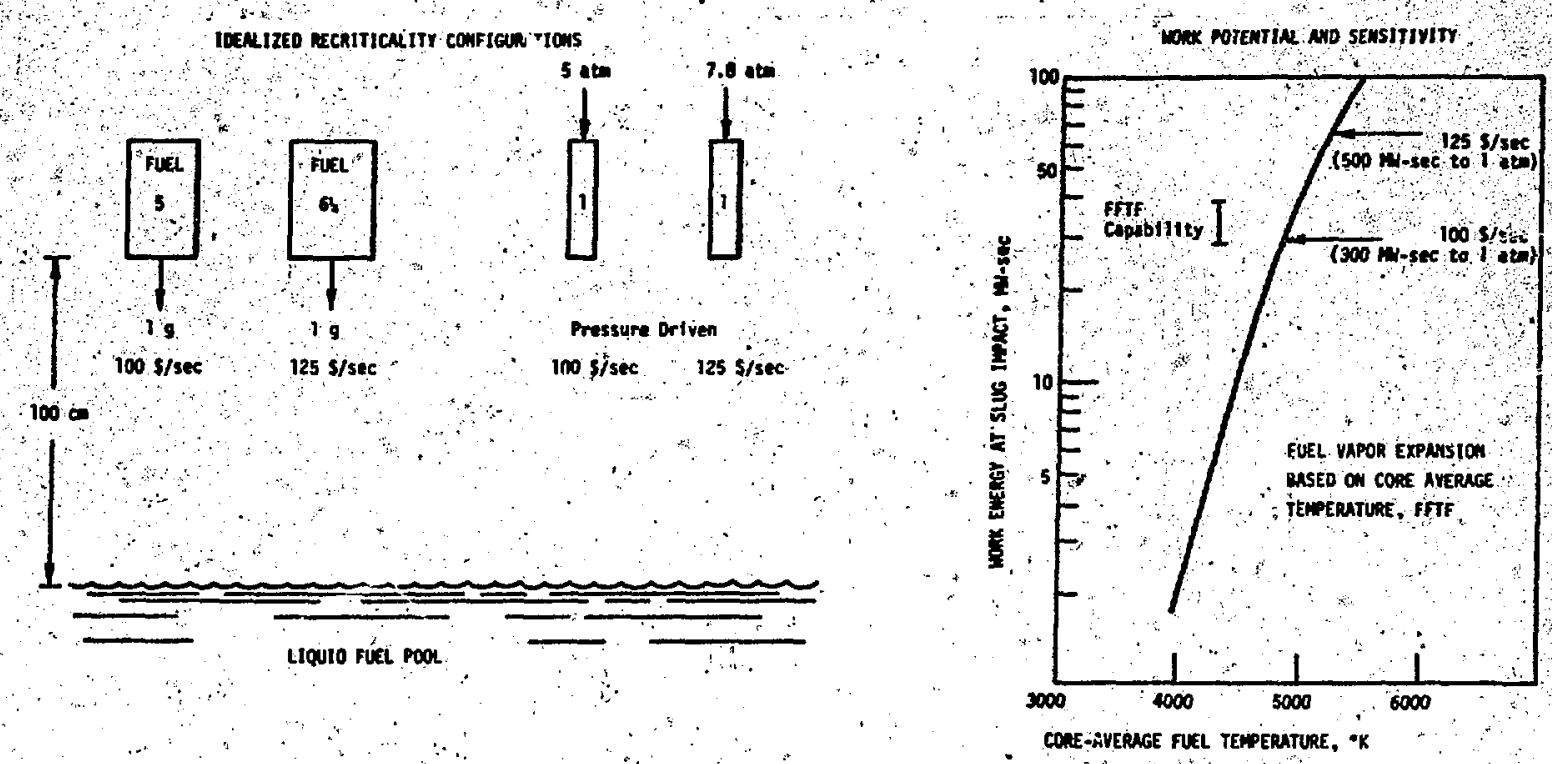

Fig. 2. Ilustration of Energetic Recriticality Events (Gravity and Pressure Driven) and Associated Work Potentials. Illustrations are made for FE where 1 unit of fuel represents the fuel Inventory in 1 subassembly. For CRBR, 1 unit woula correspond to $n 3$ subassemblies.

However, since we are dealing with low probability event:s and therefore the problem is what consequences would. result if a large frastion of the core fuel should become disrupted, in some unspecified way (known initiators which could mechanisticaliy lead to core meltdown should be prevented by design features) and thereby provide the possiblilties for either rapid coherent fuel compaction and/or energetic thermal interaction's between disrupted fuel and coolant, the only aviliable option would appear to be the last one. The recommended approach to the resolution "of the generic issues is based on a few general physical principles as follows:

1. A self-heated liquid becomes dispersive. At nominal IMFBR power level, the fuel is monotonj sally dispersive and can remain in a is -jhly boiled-up gtate down to and incluading decay-heat power levels. . (The separated fuel picture in Fig. 1 should be replaced by the bólled-up configuration).

2. Fine mixing of a cold and hot fluid, a necessary condition for developing sustained pressures and large damage potential from thermal interactions, requires spontaneous nucleation on contact. The contact temperature for the mixed oxide-fuet-sodium system is well below the spontaneous nucleation tempernture for liquid sodium. (The picture of tinely mixed molten fuel and liquid sodium in Fig. I should be replaced by the separated configuration).
The application of these two general behavior principles to an oxide-fueled LMFBR leads to the following conclusions regarding generie accident energetics issues : *

- Principles 1 and 2 rule out gravity and pressure driven recriticality.

- Principle 2 rules out energetic fuel-coolant thermal interactions (vapor explosions).

Further details pertaining to the two principles are given below.

\section{First General Behavior Principle}

During the initial stages of a postulated core-disruptive accident (e.g., loss of flow with failure to scram in FFTF or (RBRP), fuel disruption due to release of entrapped fission gas from the fuel melt is likeiy to lead to early swelling and frothing[5] and subsequent mixing with the molten cladding material. [6] The boiling point of steel is very close to the meling point of fuel so that the molten fuel-steel mixture can be treated as a saturated liquid

Fn addition to the generic issurs of fuel com pnction and fuel-coolant irrerictions, considerations must also be given to the design-dependent issue of the large core positive sodium void coefficient "theoretically large ramp rates" and autocatalytic effects are possibia from fuel fatiures into nonvolded channels). [3] 
subjected to voluivetric heat generation. Thus hoat transfer from the fuel to the entrained steel (entrained steel particles in the fuel has been observed in the TREAT mel taown expei iments) [8] will

result in rapia steel vaporization and further aispersal and boil-up of the mixture. The above process, while complex and difficult to describe in detail. ouggests that preirradiated fuel at near nominat power levels and atove, will be monotonically dispersive from the beginning of fuel disruption following the development of an uncooled fuel pin geametry . Furthermore, if we ignore the Important early contribution due to fission gas release, the subsequent dispersal and boil-up of fuel by steel vaporization down to and including decayheat power levels can be illustrated by etraightforward application of two-phase tlow theory.

The two-phase flow stability criterion suggested by kutateladze [9] can be used to predict the flow regime boundarles in a boiling system with internal heat generation, [10]

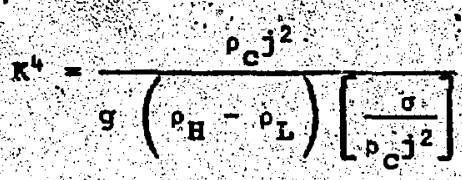

where $K$ is the Kutateladze number, $j$ is the critical upe ficlal velocity of the Iighter fluid phase, $\rho_{c}$ is the density of the cont inuous phase, of is the surface tension of the heavy fluid, and $\rho_{H}$ and pr are the densities of the heavier and Ifghter fluid, reapectively. Note that $x^{4}$ is the ratio of the dynami c pressure $\left(\sim p_{\mathrm{j}^{2}}{ }^{2}\right)$ exerted on particles of the discontinuous phase to the weight of the heavier fluid. The bracketed term in the denominator of Eq. (1) is proportional to the maximum particle dimension based on mechanical stability criteria such as the Weber number or the Kelvin-Helmaltz wavelength. I, other wora's; the kutateladze citerion is simply that baflance between dynamic pressure for drag) and buoyancy forces that is con-istent with fluid particle stability $\mathrm{k}$ takes on various values depending upon the flow regime transition under consideration, Based primarily on two-component data in the absence of heating, the transition between bubbiy flow and churn-turbulent flow is characterized by $R \sim 3$ and $\left.p_{c}=\rho_{H} .[1]\right]$ Based again on primarily two-component data and interpretation of critical heat flux occurrence
In liquid pools with external heat generation, [9] the transition from chuin turbulent to a fluidized aroplet regime. 1 a characterized by $R \sim 0.14$ and $\rho_{C}=$ plo For fuel with internal heat generation, the corresponaing super ficial vapor velocity is given by

$$
j=\frac{, q}{p_{L} h_{f g}}
$$

where $q$ is the equivalent surface heat flux corresponding to volumetric heat generation in a given fraction of the total fuel inventory that is converted to latent heat of evaporation, $h_{f g}$. By eliminating, $j$ between Eqs. (1) and (2), the flow regime boundaries for a boiling fuel-steel system can be constructed as shown in fig. 3 .

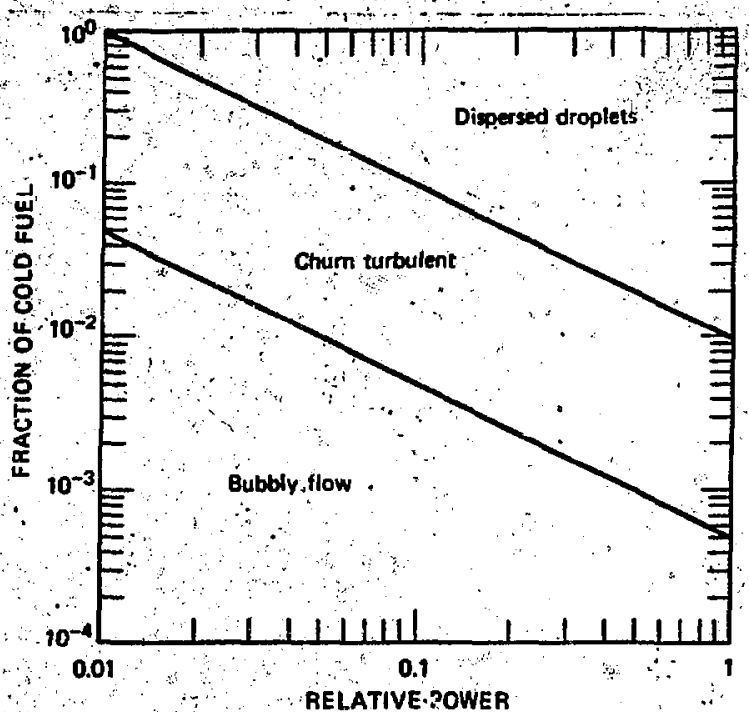

FIg. 3. FIow Regimes in a Boiling Fuel-steel Pool. [IO]

It follows that for a given equilibrium condition, the magnitude of boil-up and fuel transport outside the active core region depends vpon the flow regime. If the vapor continuotis regime prevails (1-iquid fuel and steel droplets surrounded by vapor), this leads to maximum vapor drift (or maximum slip) and hence represents the minimum boil-up condition. Assuming stagnant liquid condition, the maximum vapor drift velocity is given by

$1=\alpha^{n} v$

Where $a$ is the local void fraction and $v_{-}$ is the terminal velocity of a single 
particle in an infinite fluid medium. Using WaIlis [1:] recommended value for $n$ and $v_{6}$ (these are determined from steadystate requirements with two-component gystems with no heat generation) results in

$j=1.4 a^{2} \rho_{L}^{-\frac{1}{2}}\left[\left(\rho_{H}-\rho_{L}\right) \sigma g\right]^{\frac{2}{4}}$

It should be noted that Eq. (4) repregents the necessary vapor velocity to sustain incipient fluiaization over the whole range of void fraction values while Eq. (1) represents only the initiation of incipient fluidization which has been observed to occur at a void fraction of approximately 0,38 in two-component syctems, and may be as low as, 0.3 in hoated systems (boiling off a hot surface) $[9,11]$

similarly, if the liquid continuous regime prevails (vapor bubbles imbedded In liquid fuel and steel), this leads to minimum vapor drift (minimum siip) and hence represents the maximum boil-up condition. The vapor drift velocity for this regime is given by

$j=a(1-a)^{n-1} v_{\infty}$

Again using wallis'[i1] recommended values for $n$ and $v_{\text {e }}$ for the bubbly and foamy regimes results in

$J=1.53 \alpha(1-\alpha) \rho_{H}^{-\frac{3}{2}}\left[\left(\rho_{H}-\rho_{I}\right) \sigma g\right]^{\frac{2}{4}}$

while zuber's [11] recommended value of $n$ equal to zero for the limited churnturbulent regimes results in

$J=1.53 \frac{\alpha}{1-\alpha} \rho_{H}^{-\frac{1}{2}}\left[\left(\rho_{H}-\rho_{L}\right) \sigma g\right]^{\frac{1}{4}}$

Vold proflles relating to the steadystate boil-up condition for a given internal heat generation, 9 , can be obtained by integration of Eq. (8)

$\frac{d f}{d z}=\frac{g^{\prime}(1-\alpha)}{h_{f g^{\rho}} L}$

together wt th the Individual flux functions [Egs, (4), (6), and (7)], where $q^{\prime}$ ? is the volumetric heat generation in the fuel-steel mixture. In this way the inherent dispersive nature of the heat gererating fuel in an LMFBR can be readily. demonstrated Figures 4 and 5 lilustrate. calculations for two different equilibrium conaitions. If all the fuel is to remain within the active fuel zone (Fig. 4a) the corresponding pressure to satisfy heat reroval by upward vapor transport must be large (Fig. 4b). Therefrie in the absence of plugging extended fuel dispersal will take place leaving behind a very small amount of liquid fuel in the active zone (Fig. 5). Early fuel dispersal for near nc ninal power levels is clearly illustrated in Fig. $5 a$ even for the condition of maxinum vapot slippage. Likewise, Fig. 5 b illustrates that boil-up will even prevent a criticality configuration at 18 of nominaz power. The latter 4 calculation is based upon the chirnturbulent regime and would appear to be on the conservative side based upon recent experiments using water in $a$ microwave oven to simulate decay-heat power levels.[12] For superficial vapor velocities exceeding the bubbly flow regime ( $\mathrm{K} 0.3$ and $\mathrm{o}_{\mathrm{C}}=\mathrm{\rho}_{H}$ ), rapid boilup and a foamy regime were observed in good agreement with Eq. $(6)$ over tha whole range of void fraction values, rather than a transition to churnturbulent flow as indicated by Fig. 3 . Anaiytical studies of the above transient boil-up.process have also been provided by epstein and condiff. $[14-17]$

However, in the case that the core becomes "bottled" up, t* the quas $i-$ equilibrium conditions of the boiling pool may be better represented by the flow regime boundaries iliustrated in Fig. 3 and the void profiles according to. Figs 4 and 5 Axial and radial heat. losses In this situation would promote boil-up rather than encourage liquidvapor separation due to pressurization as observed with volumetric boiling of water in a closed container again using the microwave oven technique. [12] since the melting point of the steel confinement boundary is weli below the meling point of fuel, this necessitates the presence of a solid fuel crust. Fur thermore, since the boiling point of steel is.:approximately equal to the melting point of fuel, the maximum nonbolling layer is given by

$\sigma=\sqrt{2 k\left(T_{f, M}-T_{s, M}\right) / q}$

Startup from a Ifquid pool at its saturation temperature with internal heat generation and the presence of ample nuclètion sites, foan regine ifght be inevitable if the tate of noid growth always exceeds the rate of bubble rive" and igglowernticn thereby "locking" the bubbles into a foan regime, [13]

* thhig ma turn out to be a nonproblem. since evidence for the absence of fuel plugging is

beglining to energe. [18] 


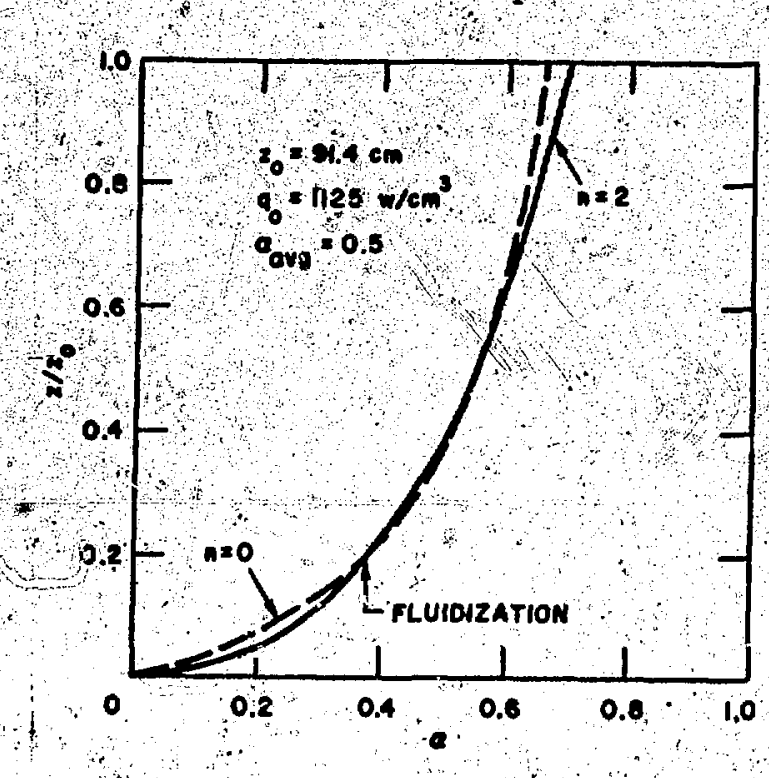

(a)

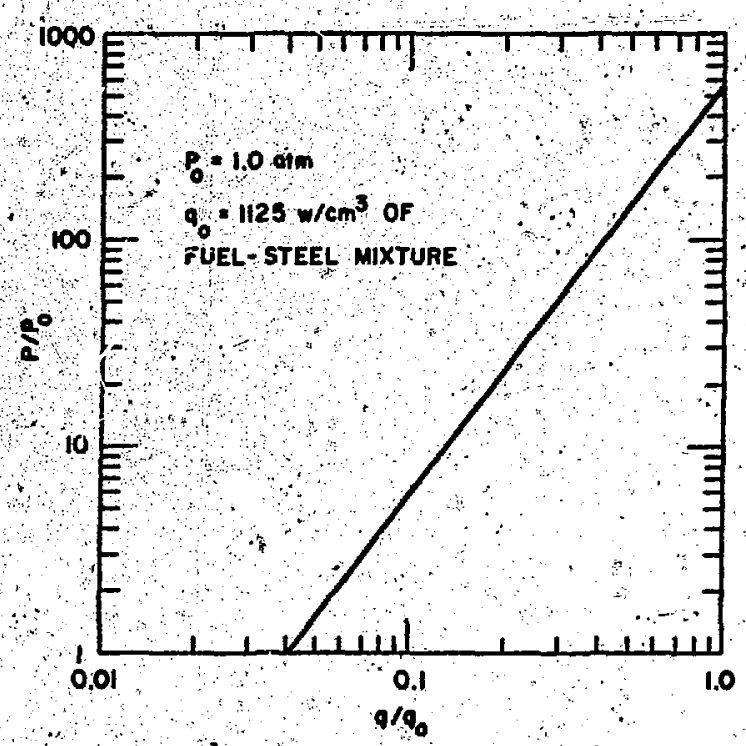

(b)

Flg. 4. Illustration of Equllibriu vold profiles and corresponding Pressure Levels with Al1 the Fuel Located within the Active Fuel zone. (a) void profiles are based upon two different flux functLoas for describing vapor drift through an essentialiy stationary liguid $n$ - o corresponds to churn-turbulint flow acconding to zuber, while $\mathrm{n}-2$ corresponds to the continuous vapor-like roglwe with fluidization generaliy occurring at a void fraction of no. 38 . The latter flux function gives maimu vapor drdft and hence resuits in the minimum boil-up condition. (b) Required prossure levels in order to remove all the generated heat finth axial direction. calculations bised upon maimum vapor drfft velocities.

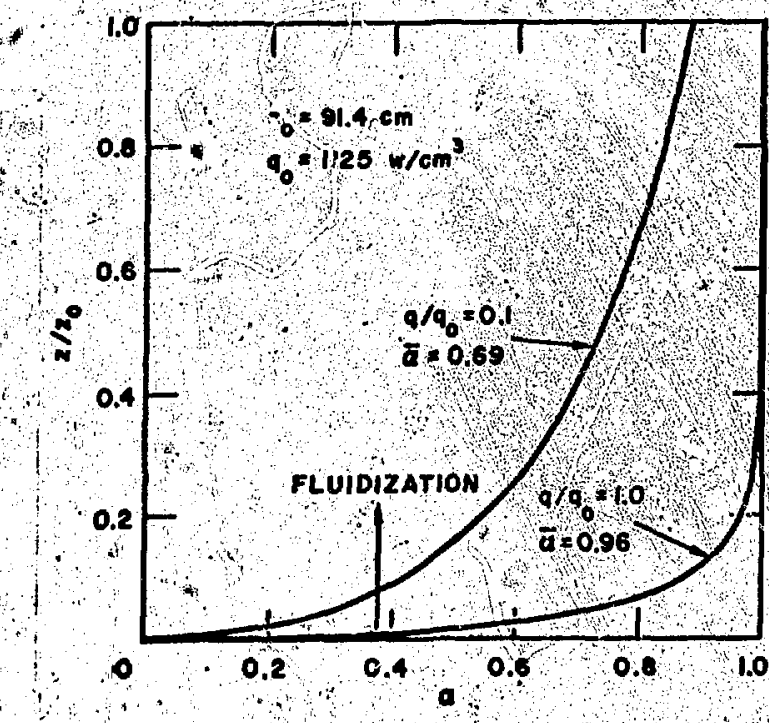

(a)

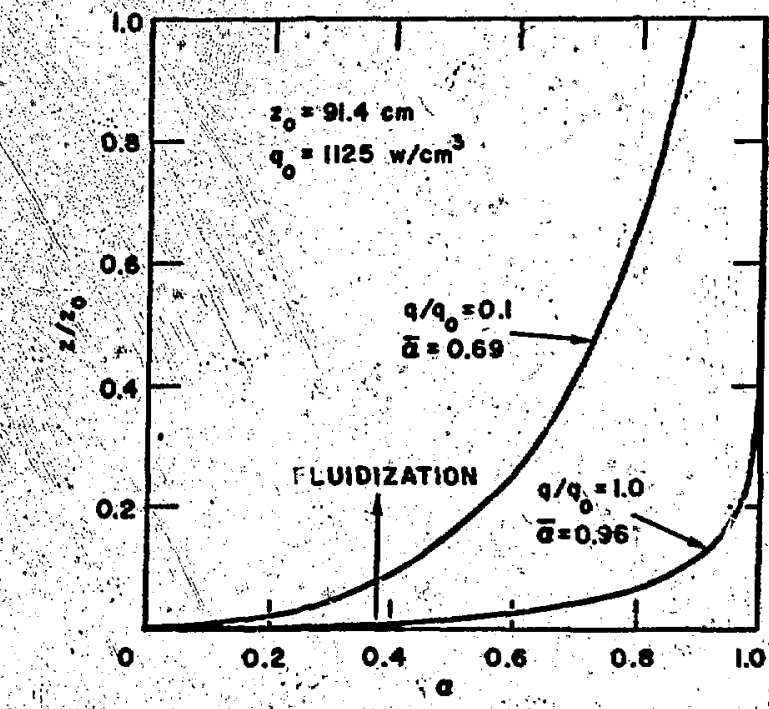

(b)

flg. 5. vquilibrium vold proflles within the fotive rud zone at 1 atm. (a) Based upon the flux function reaulting in maximum vapor drift through the stationary liquid. (b) Based upon the fiux function corresponding to churn-turbulent flow segime. 
where $T_{f, M}$ and $T_{S, M}$ are the melting temperatures for fuel and steel, respectively. The values of the crust thickness listed in Table 1 would approximate the situation in an open system (corresponding to essentially no radial heat losses from the dispersed fuel in the active core region) while recuced values would be expected in a "bottledup" system experiencing pressurizaticn (implying radial heat losses). In the latter case the crust will provide a regulating effect and significant pressurization from decay heating appears therefore very unlikely.

In adition to further analysis and creative laboratory experiments, demonstration with real reactor materials (inpile tests) appear desirable in order to achieve general acceptance of the inherent dispersive nature of oxide fuel and the absence of the potential for energetic recriticality events. The objective of the in-pile tests would be to verify the dispersive behavior of a fuelsteel mixture starting from l) the initial pin structure configuration (at nominal power or above) and 2) an initially separated state (at decay heat power levejs). The question of early monotonic fuel dispersal can be adequately assessed by TREAT with modest improvements (TKEAT Upgrade) $[19,20]$ and the SLSF program (37- and 61-pin bundle tests should be adequate). For demonstration of boil-up at decay heat power levels it is of utmost importance to recognize the inherent effect of boundary heat losses which are contrclled by the presence. of the fuel crust. As seen from Table 1 , for any significant portion of the core undergoing a hypothetical disruption; the material associated with the fuel crust at the confinement boundary only represents a small fraction of the disrupted fuel. However, this ratio is highly dependent on the silrface-to-volume ratio of the sample in question and indeed becomes quite large or even exceeds 1 for fuel sample sizes of the order of a single IMFBR subassembly (i.e., in the range of the capability provided by the 'planned SAREF program) $[18,19]$ Melting down fuel pin samples of this size (much larger samples are not considered practicablel; with the objective of verifying fuel dispersal at decay heat power levels most likely would lead to highiy nonprototypic and highly undesirable results. This objective can, however, be achieved with reasonable samp's sizes, by, influding as part of the lickeup of the test fuel sample (see Fig. 6 ), the nonboiling fuel layer at the confinement boundary. as it would be present in hypothetical core melclown situations as discussed above. By providing for the fuel crust prior to boil-up in the small sample (geometric dimensions illuetrated in Fig. 6


Fig. 6. Proposed In-pile Test Sample for Resoiu-
tion of Key Recriticality Issues.

corresponds approximately to an equivalent 61-pin bundle test), an essentially adiabatic system is established much like in the hypothetical large system. Because of the large time constant of the fuei, the required energy deposition in both the crust and the fuel sample (should. approach the melting. point of the crust Erior to boil-up of the fuel sample) can be achieved by a power burst prior to the flattop simulating decay heat power level (see Fig. 6). It is suggested that the proposed test sample in Fig. 6 can be used as a reference for a test matrix that 'could include separate effects prooftests of the following nature: 1) boil-up in an initially open system including measurements of the rate of fuel dispersal and fuel penetration into the upper simulated blan'et and fission gas plenum regions to verify current analysis $[7,10]$ and out-of-pile experiments as they relate to boil-up tests with simulant materials [12] and freesing and plugging tests using the thermise method to produce molten fuel, [1B] 2) the 
rable 1 Fue 1 crust characteristics

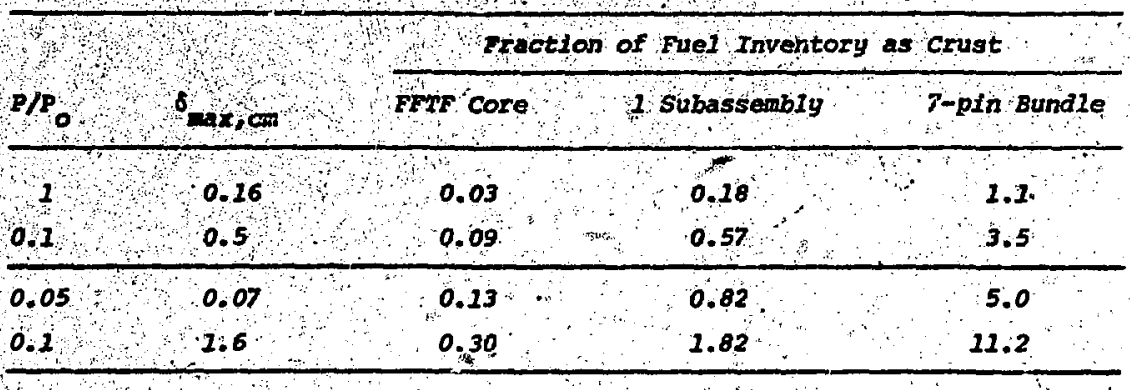

potential for pressure drfiven compaction by including the presence of liquid sodium in the simulated blanket and fiasion gas plenum regions to verify current analysis [3] and out-of-pile experiments using the thermite method, [21] and 3) boil-up in a "bottled-up" system including measurements of potential pressurization, [12] stability of the crust Iayer [22] and rate of unplugging to verify current analyois and out-of-pile experiments. [18] The above proposed test matrix should provide adequate resolution (pubilc acceptance) to the recriticality question for LMFBRs and would not appear to require fuél sample sizes exceeding the capability being provided by TREAT Upgrade within the proposed SAREF program. $[19,20]$

3. Second General Behavior Principle General agreement now appears to omerge in the technical literature that the contact temperature $T_{f}$, determinad: from

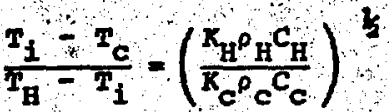

exceeds the spontaneous nucleation temperature $T_{*}^{*}$ deternined from

$J=N_{L} \exp \frac{N}{k T} \operatorname{L}(a)$

in all observed energetio large-inass vapor explostons between a hot and a cold fluid (see Fig. 7), where $\mathrm{K}$ = thermal conductivity, $p=$ density, $C$ - speciffc

TI shond at the deverly Hil18 Fest nelactor safoty ninting, [23] this nucleation thresholld is dapendent cn both contect materand contact time. These effects can be represonted by specifying the contant angle a (see Fig. 8 ), Fbr the iolten $\omega_{2}-N a$ syatem, $\alpha$ is believed to have, vilue botwen o and 90
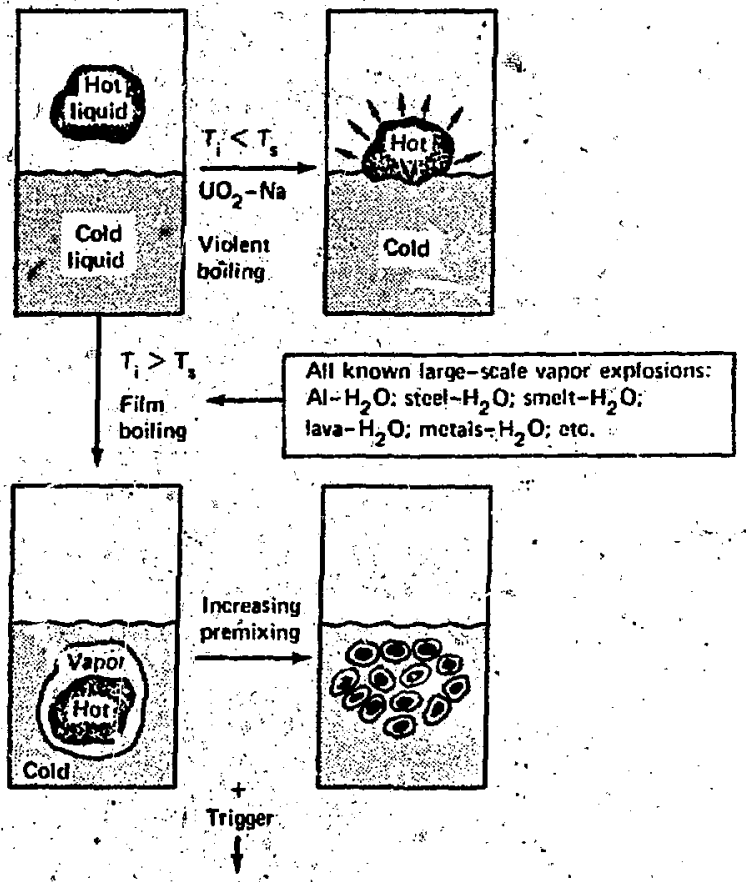

Large-scale vapor explosion

81g. 7. Requirenents for Premixing and Development of Pressure Generation and Largesciale vapor Ixplosion. $T_{i}$ is the tnterface temperature upon contact and Is Is the spontaneous nucleation temperature of the cold fluid.:

heat, subscripts $H$ and $c=$ hot and cold 1.quids, respectively, $\mathrm{N}_{\mathrm{L}}=$ the number of molecules per unit volume of liquid, $\omega=$ a constant with a numerical value close to $20^{10} 0^{-1}, k=$ the Boltzmann constant, $W$ - the reversible work of formation of the critical embryo froun the liquid, and $f(a)$ i function of contact angle a. This threahold condition, which has been verified experimentally with a number of 1iquid-1iquid systems [23-27] was discussed by Fauske at the second CSNI. Heeting on Fuel-coolant Interaction in terms of two requirements: $[28]$ 


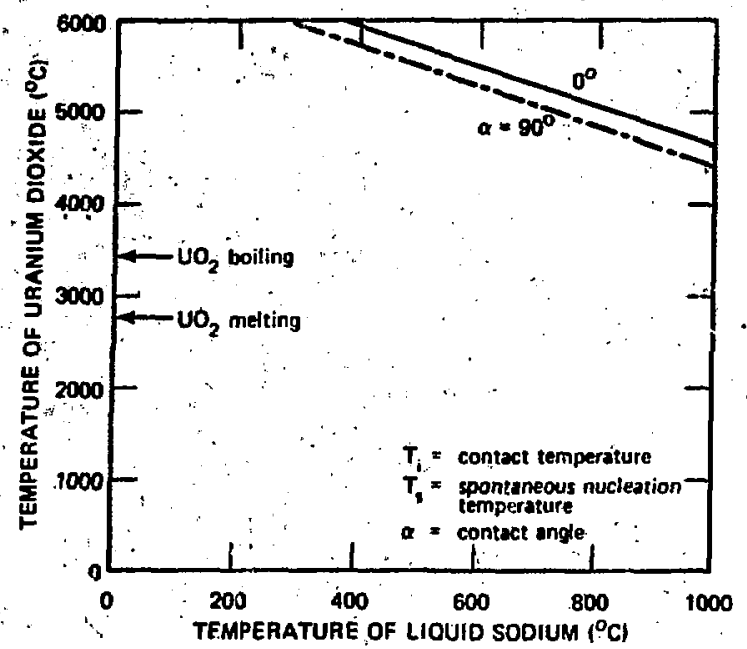

Fig. 8. IIIustration that Sportaneous Nucleation is Unlikely to be Reached upon Contact between HoIten Oxide Fuel and LIquid sodium for remperatures of Interest.

1) spontaneous nucieation allows for film bolling and therefore provides for the necessary initial intermixing of the cold and hot fluids, and 2) also allows for "continuous explosive boi.jing" to initiate or trigger the large-mass explosion when sufficient liquid-liquid contact and required constraint are established (see Fig. 71 .

As seen in Fig. 8, for the $\mathrm{UO}_{2}-\mathrm{Na}$ system the contact temperature $T_{i}-i s$ well below the spontaneous nucleation temperature $T_{S}$ for temperatures of incerest, thereby suggesting that; sustained pressure generation with these materials due to lack of the necessary intermixing and trigger is not possible. This observation is consistent with well over iuv interaction tests with IMFBR materials (molten $\mathrm{UO}_{2}$, mixed oxide, molten steel and liquid sodium) including various contact modes (fuel injection above and below the liquid sodium surface, fuel dropping, fuel squirting, sodiun injection above and below the molten fuel surface, etc.) ana simulated accident sequences (loss of flow and overpower transients including prompt burst simulations), and includes tests with moltenfuel inventory in the kilogrami range. [29] All of these tests, which include both out-of-pile and at least 50 in-pile. varieties; have consistientily demonstrated very mild thermal interactions, in agreement with the general behavior principle. only the small-scale laboratory experimonts carried out by Armstrong, [30] in which a small jet of liquid sodium was injected into a crucible of molten $\mathrm{UO}_{2}$, have produced thermal interactions with significant above-surface shock waves. The observed interaction was first interpreted by Fauske as follows. [31] when liquid sodium is injected into molten. $\mathrm{UO}_{2}$, some of the liquid sodium will be entrained and wet the molten $\mathrm{vO}_{2}$ surface (which in the ideal laboratory experiment can be considered free of gas bubbles). Because of lack of nucleation sites in the liquid-liquid system (subsequent $\mathrm{UO}_{2}$ freezing is not important if gas is absent), the scdium temperature is raised to the temperatire limit corresponding to spontaneous nucleation (see Fig. 9). When

\section{LABORATORY CONTACT MODES}

$\mathrm{UO}_{2}$ - $\mathrm{Na}$ SYSTEM
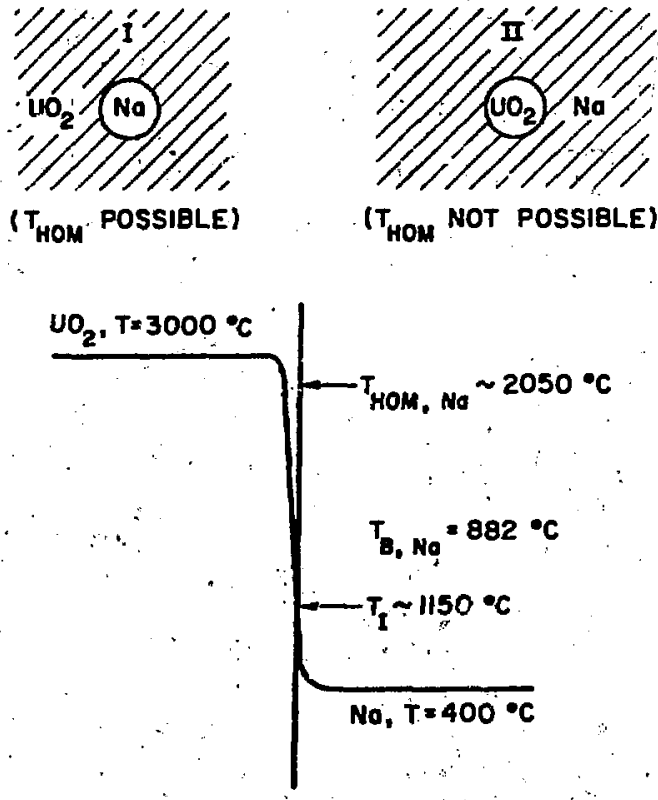

Fig. 9. Illustration of Different Behavior in Idealized Iaboratoiy Experiments with small Quantities of Molten Fuel and Liquid Sodium! I - Na Injected into $\mathrm{UO}_{2}$, $I I-U_{2}$ Injected into Na. THON homogeneous nucleation temperature for liquid scdium, $\mathrm{T}_{\mathrm{B}, \mathrm{Na}}=$ normal boiling temperature for $\mathrm{Na}$ at $1 \mathrm{~atm}$.$$
\cdots
$$

this temperature is reached, vaporization is rapid enough to produce shock waves. This interpretation implies that in a real reactor system, even a small-mass vapor explosion as observed in Armstrong's experiments would be difficult because of the ample supply of pre-existing nucleation sites.

However, while experiments with molten $\mathrm{UO}_{2}$ and sodium and with other simulant fluids appear to confirm the second general behavior principle, it 
ohould be noted for completeness that it has not been generally accepted in the technical comunity For example, Boara and Hal1 [32] claim that spontaneous nucleation cannot be the source of rapid generation of vapor for the explosions (this witter obviously disagrees) and suggest the above criterion may determine only the initial conditions for the explosion and is not relevant to the process or explosion development. and "it is not possible to rule out large-scale fragmentation explosions if there are any other circumstances which could lead to relevant initial conditions " Hopefully, these fundamental differences as they relate specificaliy" to the nole and type of nucleation in the explosion process itself can be clarified by further laboratory experiments and detailed anclysj.s of the type discussed in Ref. 33 .

\section{References}

[1] $\mathrm{H} \mathrm{A}$ Bethe and J. Hait, "An Estimate of the order, of Magni tude of the Explosion when the core of a Fast Reactor Collapses," British Report RHM (56)/113, 1956 .

[2] E P. Hicks and D. C. Menzies, Theoretical studies on the Fast Reactor Maximum Accident," Proc. of conf. on safety, Fuels, and Core Dem sign in Iarge Fast Powe keactors, oct. 11-14, 1965, ANL-7,20, Argonne National Laboratory, pp. $65.4-670$, 1965.

[3] H. K. Fauske, "The Role of coreDisruptive Accidents in Design and uicensing of IMFBRs," Nucleaj Safety. Vol 17 No 5 , sept.-Oct $197 t^{\circ}$.

[4] J. $F$. Marchaterre, "qverview of coreDisruptive Accidents," proceedings of this meeting.

[5] I. Deitrich et al, "Modeling the Response of Fast Reactor Fuel to Accident Transients," Proc. Intl. Mtg. on Fast Reactor Safety and Related Physics, chicago, Iflinois, oct. $5-8$, 1976 .

[6] H. K. Fauske, Some comments on Cladaing and Eariy Fuel Relocation In LMFBR Core-Disruptive Accidents," Trans. Am. Nucl. Soc. 21 , pp." 322$323,1975$.

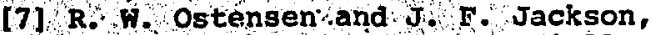
"Dynainde Behavior of a gartially Mólten LMFBR Core ontans, Ann. Nucl. Soc..17.(1):220 (June 1974).

[8] C, $\mathrm{E}$. Dickerman et al "Recent Results from TREAT Tests on Fuel. cladaing and coolant Motion, "ioc. European Nuclear conf paris, Aprt1 21-25, 1975.

19/ S. S. Kutateladze wlements of the Hyarodynanics of Gas-Liquid Systems," EIuia Mechanics - Soviet Research, Vol, 1, No $4, p, 29,1972$,
[10] $\mathrm{H}$. Fauske, "Boiling Flow Recime Maps in IMFBR HCDA Analysis," Trans. Am. Nucl. Soc. 22, Pp. 385386,1975 .

[11] G. B. Walis, one-dimensional Twophase Flow, McGraw Hill Book Co. Inc. 1969 .

[12] M. Farahat, R. E. Henry, and $J$. Santori, "Fuel Dispersal Experiments with simulant Eluids, " Proc. Inti. Ntg. on Fast Reactor Safety and. Related Physics, Chicago, IIIinois, Oct.. 5-8, 1976.

[13] $M$. Epstein, personal communication, March 1977.

[14] M. Epstein, Mransient Behavior of a volume-Heated Boiling. PoOI," ASME Winter Mtg.. Paper No. 75-WA/HT-31, Houston, Texas, Dec. 1975.

[15] D. H. Condiff and $M$. Epstein, "Transient Volumetric Pool Boiling - I. Convex FIux Relations," Chem. Eng. Sci. 31, pp. 1139-1148, 1976.

[16] $D$. W. Condiff and $M$. Epstein, mransient Volumetric POOl Boiling - II. Non-Convex Flux Functions," Chem. Eng: Sci., 31, pp. 1149-1161, 1976 .

[17] D. W. Condiff, M. Epstein, and M. A. Grolmes, "Transient Volumetric Pool Boiling "with Foaming," to be published in Chem. Eng. progr.. Symposium Series, 1977.

[18] M. Epstein et al. "Analytical añ Experimental studies of Transient Fuel Freering," Proc. Intl. Mtg * on Fast Reactor Safety and Related Physics, Chicago, Illinois, oct. 5-8, 1976:

[19] R. Avery et al., "The SAREF Program," Proc. Intl. Mtg. on Fast Reactor Safety and Related Physics,"Chicago, Illinois, oct. 5-8, 1976.

[20] M. A. Grolmes et al. "In-pile Experiments and Test Favilities Proposed for Fast Reactor Safety," Proc. Intl. Mtg: on Fast Reactor Safety and Related Physics, Chicago, Iilinois, Det. 5-8, 7.976 .

[21] R. E. Henry et al. "Experiments on Pressure-Driven Fuel Compaction with Reactor Materials," Proc. Intl. Mtg. on Recctor Safety and Related Physics, Chicago, Illinois, Oct. 5-8, 1976 .

[22] M. Epstein, "Stability of a Submerged Frozen Crust, ASME Winter Mtg ., Paper No: 76-WA/HT-31, New York, New York, Dec. 1976.

[23] H. K. Fauske, "Some Aspects of IiquidHiquid Heat Transfer and Explosive Boiling Proc: Fast Reactor Safety Mtg. Betrarly Hills, California, Apri1 2.4, 1974, CONF-740401.

[24] R. Heriry et al." "Large-Scale Vapor Explosions," Proc. Fast Reactor Safety Mtg - Beverly Hills, california, April 2-4, 1574. CONE-740401. 
[25] R. E. Henry, H. K. Fauske, and L. M. McUmber, "Vapor Explosions with Subcooled "Freon" Trans. Am. Nucl. Soc. 21, 1975.

[26] Miander and J. I. Katz, "Bubble Nucleation in Iiquids," AIChE Journal, 21. No. 5 , Sept. 1975 .

[27] R. C. Reid, "Superheated Liquids," American Scientist, 64 , No: 2 , pp. 146-I56, March-April 1976.

[28] H. K. Fauske, "Mechanisms of LiquidLiquid Contact and Heat Transfer Related to Fuel-Coolant Interactions," Proc. Second Specialist Meeting on Sodium Fuel. Interaction in Fdst Reactors, Ispra, Italy, Nov. 21-23, 1973.

[29] H. K. Fauske, "CSNI Meeting on FuelCoolant Interactions," Nuclear safety, I6, No. 4, July-August 1975..

[30] $\bar{D}_{0}$. R. Armstrong, G.: T. Goldfuss; and R. H. Gebner, "Explosive Interaction of MoIten $\mathrm{UO}_{2}$ and Iiguid Sodium, " ANL-76-24, argonne National Iaboratory, March 1 5.76 .

[31] H. K. Fauske, "On the Mechanisms of Uranium Dioxide-Sodium Explosive Interactions," Nucl:. Sci. Eng., 51, pp. 95-101, 1973.

[32] S. J. Board and R. w. Hall, "Detonation of Fue1-Coolant Explosions," Nature, 254, pp. 319-321, March 27, 1975:

[33] R. E. Henry and H. K. Fauske, "Energetics of vapor Explosions,". Paper 75-HT-66, presented at the 1975 AIChE-ASME Heat Transfer Conference, San Francisco, Californica, Aug. 11-15, 1975. 